Journal of Scientific Perspectives

Volume 3, Issue 1, Year 2019, pp. 47-58

E - ISSN: 2587-3008

URL: http://ratingacademy.com.tr/ojs/index.php/jsp

DOİ: $10.26900 /$ jsp.3.006

Research Article

\title{
A RULE OF THUMB TO DETERMINE THE LOCATION OF WI-FI MODULE ON PLASTIC OR METAL CHASSIS
}

\author{
Alper ÖZEL * \& Meriç DÖNER** \\ *Istanbul Technical University, Faculty of Electrical Engineering, Department of Electronics and \\ Communication Engineering, TURKEY, E-mail:alper.ozel@arcelik.com, \\ ORCID ID: https://orcid.org/0000-0002-3929-1672 \\ ** İstanbul Technical University, Faculty of Electrical Engineering, Department of Electronics and \\ Communication Engineering, TURKEY, E-mail: meric.doner@arcelik.com,
}

ORCID ID: https://orcid.org/0000-0002-3113-6918

Received: 17 December 2018; Accepted: 29 January 2019

\begin{abstract}
In this study, a general rule of thumb was developed for an easier and more robust product configuration management containing more than one Wi-Fi modules. In the study, a television chassis is being used for two different models having different Wi-Fi modules in them. From manufacturing perspective, managing the product configuration as simple as it can improve the manufacturing costs drastically. Two Wi-Fi modules having different antenna characteristics will perform differently based on their locations on the chassis. Based on the distance of the antenna to the closest material of the chassis effects antenna characteristics of both Wi-Fi modules. We obtained a common minimum distance that does not disrupts the antenna performance of both Wi-Fi modules to out of Wi-Fi spectrum. For the particular case in this study, we obtained a safe distance which keeps the voltage standing wave ratio of the antennas of both Wi-Fi modules under two over Wi-Fi frequency spectrum.
\end{abstract}

Keywords: Wi-Fi, Wi-Fi module positioning, Wi-Fi Antenna performance.

\section{INTRODUCTION}

Wi-Fi based WLANs (Wireless Local Area Network) are widely used for Internet access. They were designed such that an Access Points (AP) serves few associated clients with symmetric uplink/downlink traffic patterns. Usage of Wi-Fi modules in televisions and in other household goods frequently experience poor performance in terms of downlink/uplink throughput, goodput and responsiveness. We study the environmental factors that are responsible for this performance degradation. We designed a Wi-Fi module for TV applications and analyze the change in antenna characteristics, antenna performance and throughput 
performance of the module for various placement locations on the chassis of the television which has metal on the inside and plastic on the outside. We find that the placement location of the module in reference to the closest distance from antenna surface to plastic or metal material surface. Due to the change in the antenna characteristics, received signal strength changes and it results in performance loss. In this study, we propose a safe method to define a rule of thumb for locating the Wi-Fi modules in household goods to guarantee an acceptable performance degradation in antenna performance. We demonstrated that maximum tolerance on Wi-Fi throughput performance can be limited by this method.

\section{MATERIAL AND METHODS}

\subsection{Importance of Antenna in Wi-Fi Systems}

A Wi-Fi transceiver has several radio frequency (RF) signal paths due to many supported frequency bands. Each of these RF signal paths contain a duplex filter, a power amplifier, a low noise amplifier, and so on, resulting in various parallel paths. All this signal paths start with antenna. The receiver system starts with the antenna listening to the transmitted, attenuated and distorted signal. Overall noise of the receiver system is conformed with the noise of the antenna and with the noise addition of every element of the receiver. According to the Friis equation [1], the first block in the chain effects the SNR (Signal to Noise Ratio) most since it's noise will be transferred through each block in the chain. Therefore, in wireless systems such as $\mathrm{Wi}-\mathrm{Fi}$, the performance of antenna plays a great role in communication performance.

\subsection{Parameters result in degrade in antenna Performance}

Printed circuit board trace antennas and stamp antennas suffer from degradation in performance due to the presence of metal surroundings by the most [2]. However, plastics and mica surroundings are also crucial to antenna performance due to the loading effects and impedance imbalance. Plastic and mica are dielectric materials and their presence near antenna results in frequency shift in the center frequency. Moreover, some of the plastic and mica materials may have higher conductivity than usual due to the paintings on them which may contain iron oxides [3]. That results in complete characteristic change in the antenna.

\subsection{The Instruments used in the study}

Two different Wi-Fi modules are used in the tests. Their circuit board sizes are the same but one has stamp antenna and the other has PCB trace antenna. Inhouse Wi-Fi module with PCB trace antenna has transceiver architecture as Single-Band IEEE 802.11n (2x2) WLAN while the other Wi-Fi module with stamp antenna has transceiver architecture as Dual-Band IEEE 802.11n (2x2) WLAN. We designed the Wi-Fi module with the PCB trace antenna for TV applications and the other one is commercially available stamp antenna Wi-Fi. They both are to be used in the same television chassis. 
Fig. 1. Single-Band IEEE 802.11n (2x2) WLAN Block Scheme

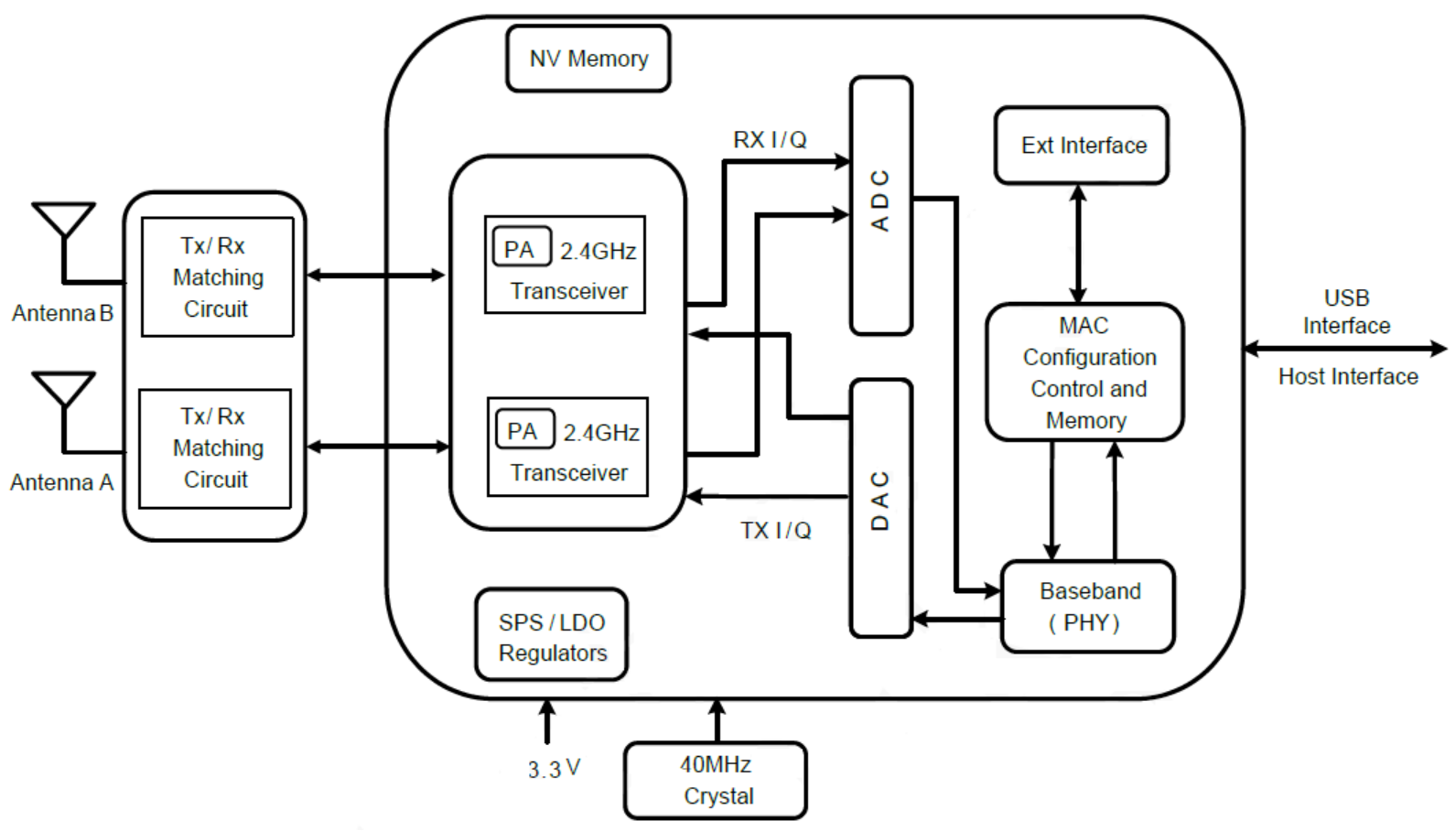

Fig. 2. Wi-Fi Module with PCB Trace Antenna

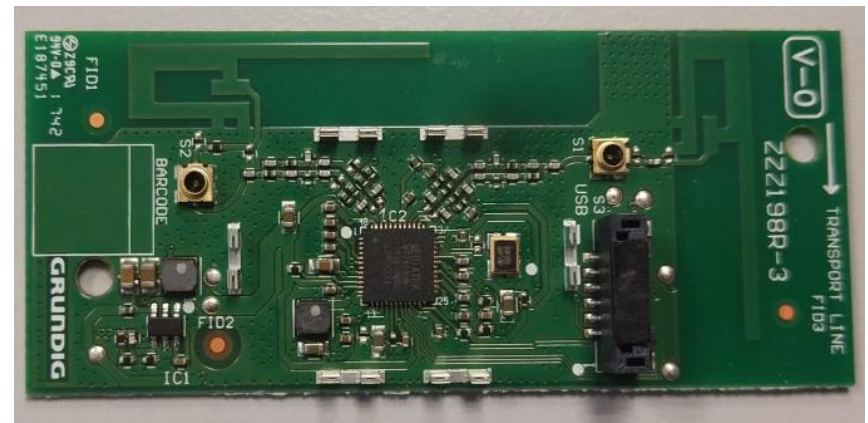


Fig. 3. Dual-Band IEEE 802.11n (2x2) WLAN Block Scheme

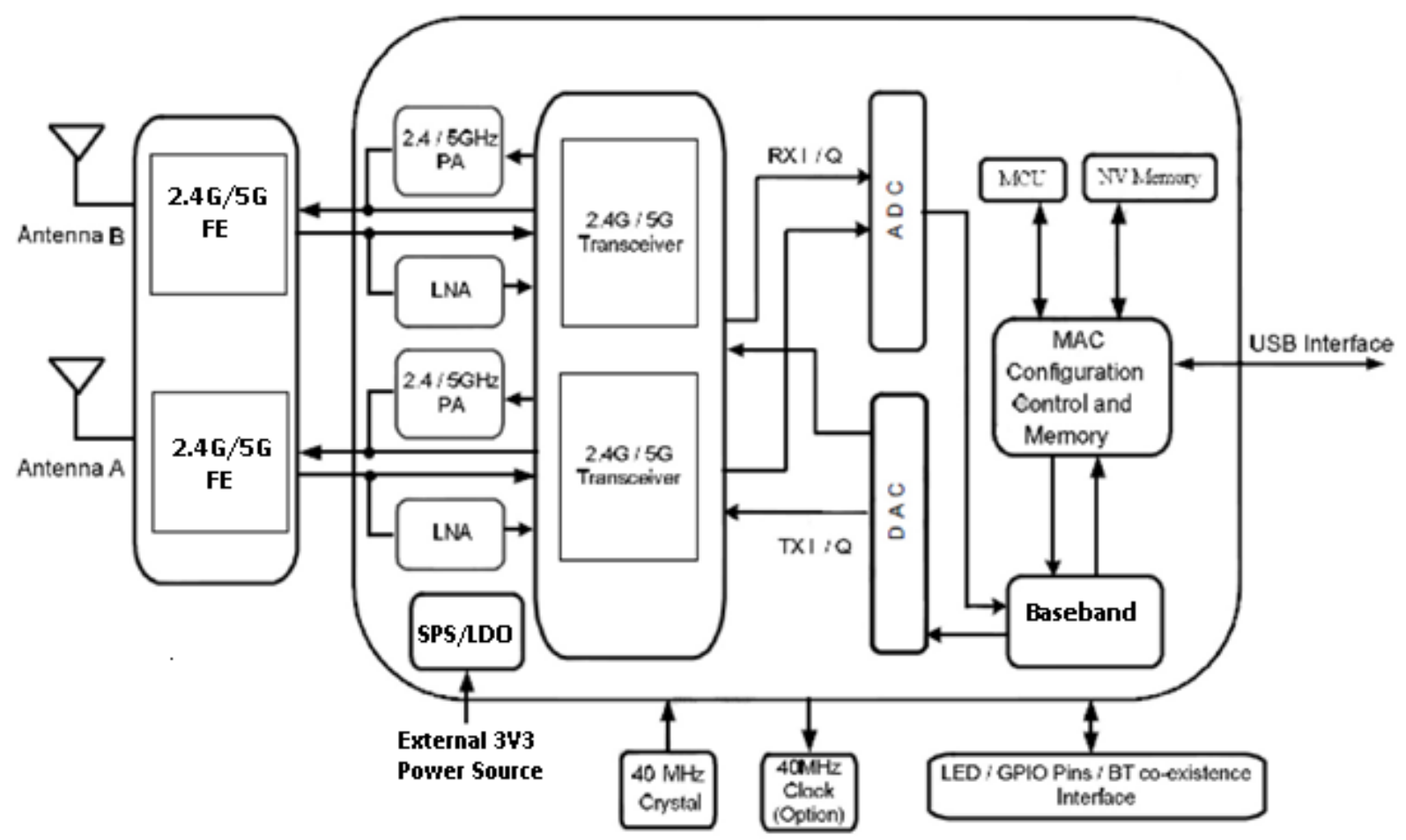

Fig. 4. Wi-Fi Module with Stamp Antenna

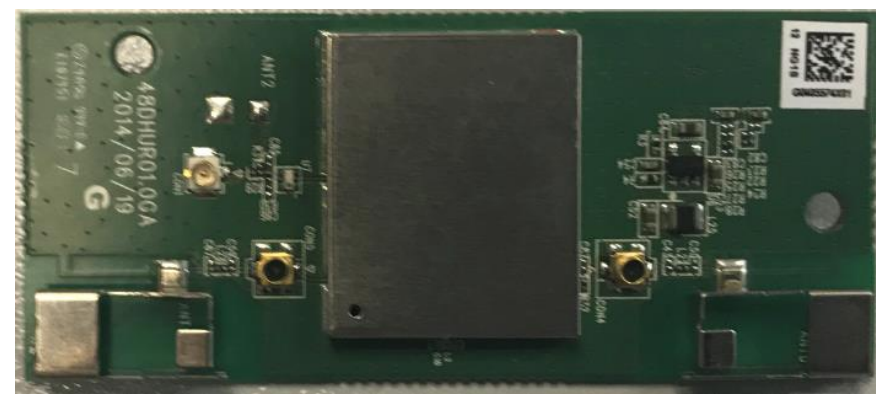

In the figures 1 and 3, system schemes of the Wi-Fi modules are demonstrated. Figure 1 shows the module which is designed by us and is a single band Wi-Fi module. Meaning it operates only in $2.4 \mathrm{GHz}$ band while the other one is dual band and operates in both $2.4 \mathrm{GHz}$ and $5 \mathrm{GHz}$ band. As seen in the schemes, the signal is first by the antennas and then travels through the front end (FE), the first part that signal goes. This part is required to have an impedance matching regarding the signals frequency band. And for the received signals fed into a low noise amplifier (LNA) which is a special amplifier designed to amplify incoming signals with a low noise contribution. On the other hand, power amplifier (PA) is designed to amplify the outgoing signal with highest efficiency. The received signal is downconverted to the baseband and the transmitted signal is upconverted to the RF carrier frequency by the transceiver. Downconverted signal is quantized by the analog-to-digital converter (ADC) and fed into the baseband. Also, transmitted signal is dequantized by the digital-to-analog converter (DAC) and fed to the transceiver. After Media Access Control (MAC) sublayer checks if the incoming data is linked to the device and permits the data transition accordingly. Also, when the device is transmitting a package, MAC sublayer always attaches the MAC ID to the package to satisfy TCP/IP protocol. 
The reference (in figure 4) and designed (in figure 2) prototypes were utilized for analyzing the influence of the proximity of antennas to different materials which are surrounding the Wi-Fi module on television (Metal and Plastic) on antenna performance. The change in antenna performance was measured with a Vector Network Analyzer (Rohde Schwarz ZNB).

For each case, each condition which has different proximity from Wi-Fi module to the material, reflection coefficient S11 and voltage standing wave ratio (VSWR) measurements are made to see direct effect of the change in the antenna performance.

\subsection{Test Method}

We connected the Wi-Fi modules' antenna ports to VNA (Vector Network Analyzer) via RF connectors and we measured their VSWR throughout the Wi-Fi frequency spectrum. VSWR is a function of the reflection coefficient, which describes the power reflected from the antenna. If the reflection coefficient is given by $\Gamma$, then the VSWR is defined by the following formula [4]:

$$
V S W R=\frac{1+|\Gamma|}{1-|\Gamma|}
$$

The VSWR is always a real and positive number for antennas. The smaller the VSWR is, the better the antenna is matched to the transmission line and the more power is delivered to the antenna. The minimum VSWR is 1.0. In this case, no power is reflected from the antenna, which is ideal. However, in many Wi-Fi applications, VSWR below 2 over the Wi-Fi band considered very good while VSWR between 2 and 3 is satisfying [5].

In the tests, firstly, VSWR characteristics of the antennas were measured in floating condition without any obstacle nearby. Then the Wi-Fi Modules are placed on metal and plastic obstacles with different distance to the obstacles and deformities in the frequency response were observed.

The test environment is shown in figures 6-8. The test method that is used to make the measurements is shown in figure 5. And the graphical outputs of the S11 measurements when the modules are in the floating conditions are shown in the figures 9-12.

Fig. 5. Illustration of the Test Method

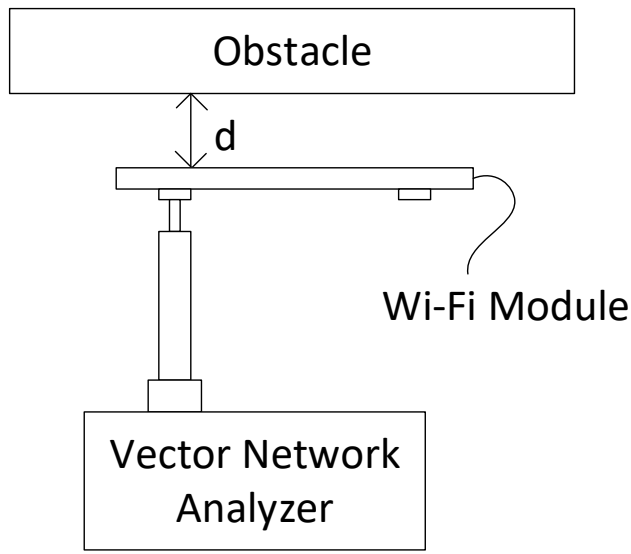


Fig. 6. Wi-Fi module in floating position.

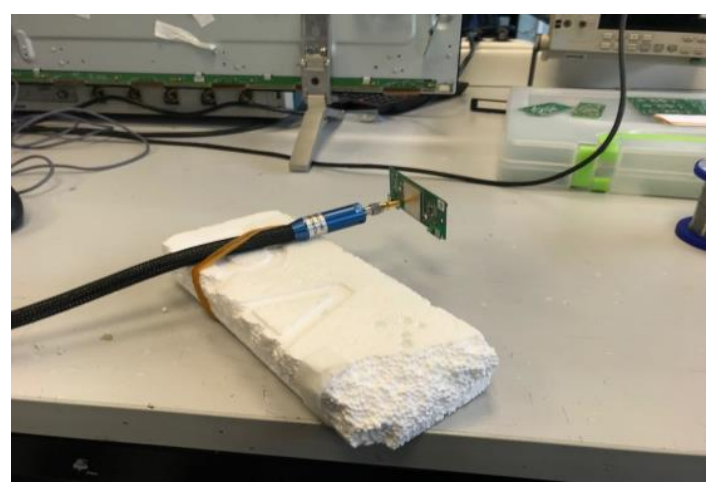

Fig. 7. Wi-Fi module placed on Metal Surface

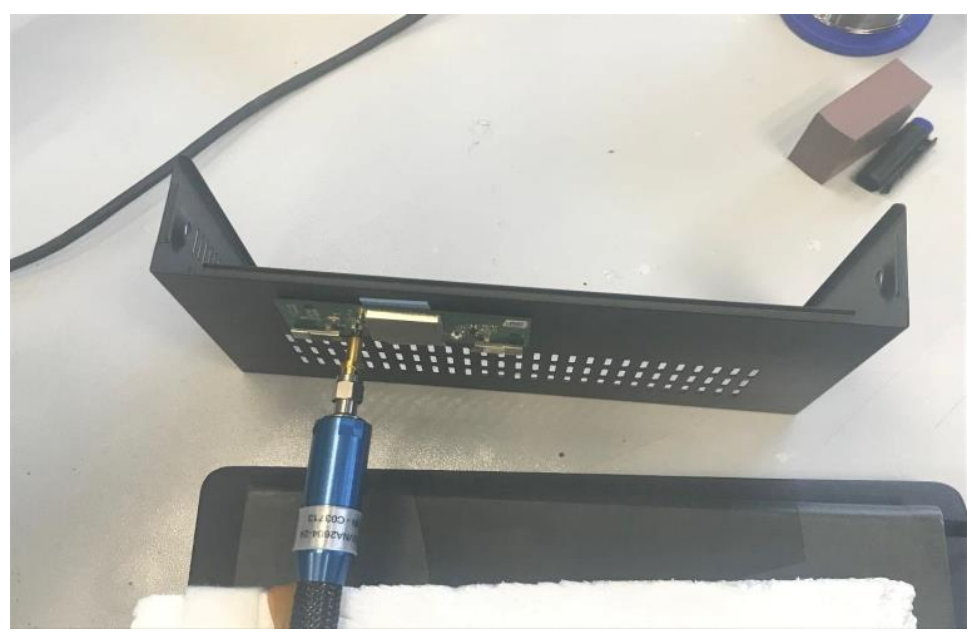

Fig. 8. Wi-Fi module placed on Plastic Surface

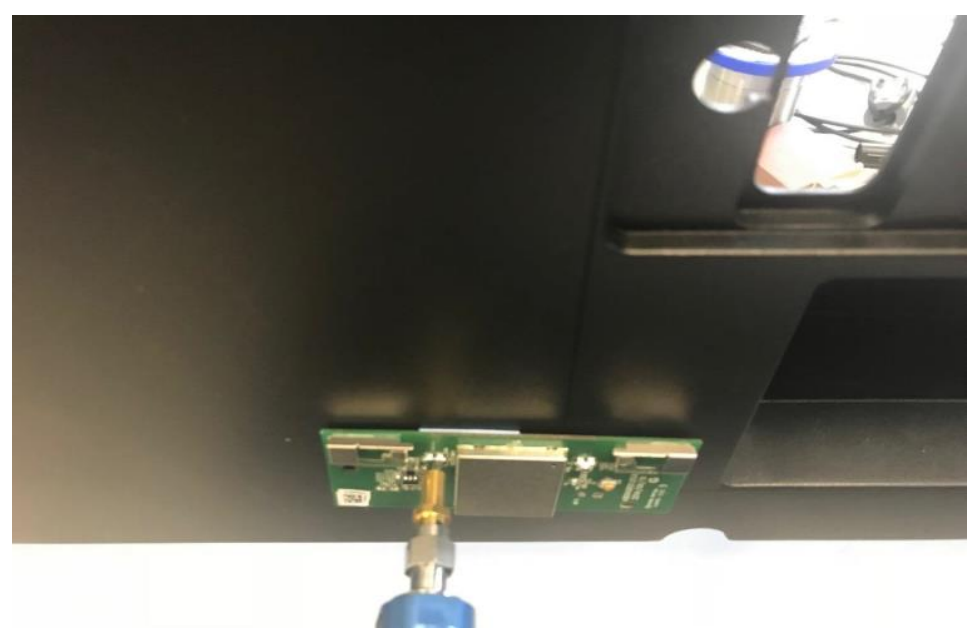


Fig. 9. VSWR of Floating Dual Band Wi-Fi Module Antenna \#1

12/1/2017 7:25:26 AM

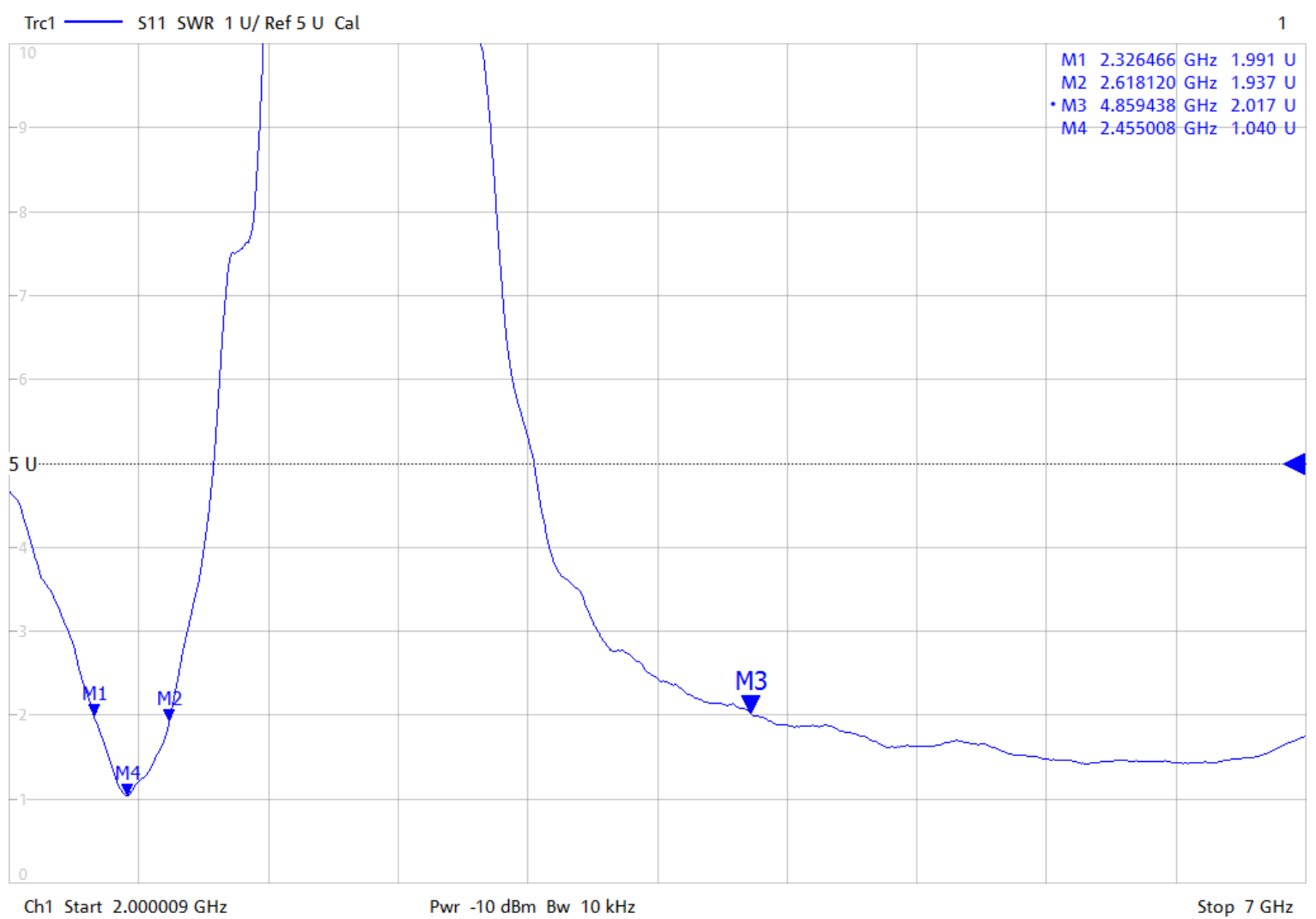

Fig. 10. VSWR of Floating Dual Band Wi-Fi Module Antenna \#2

12/1/2017 7:23:43 AM

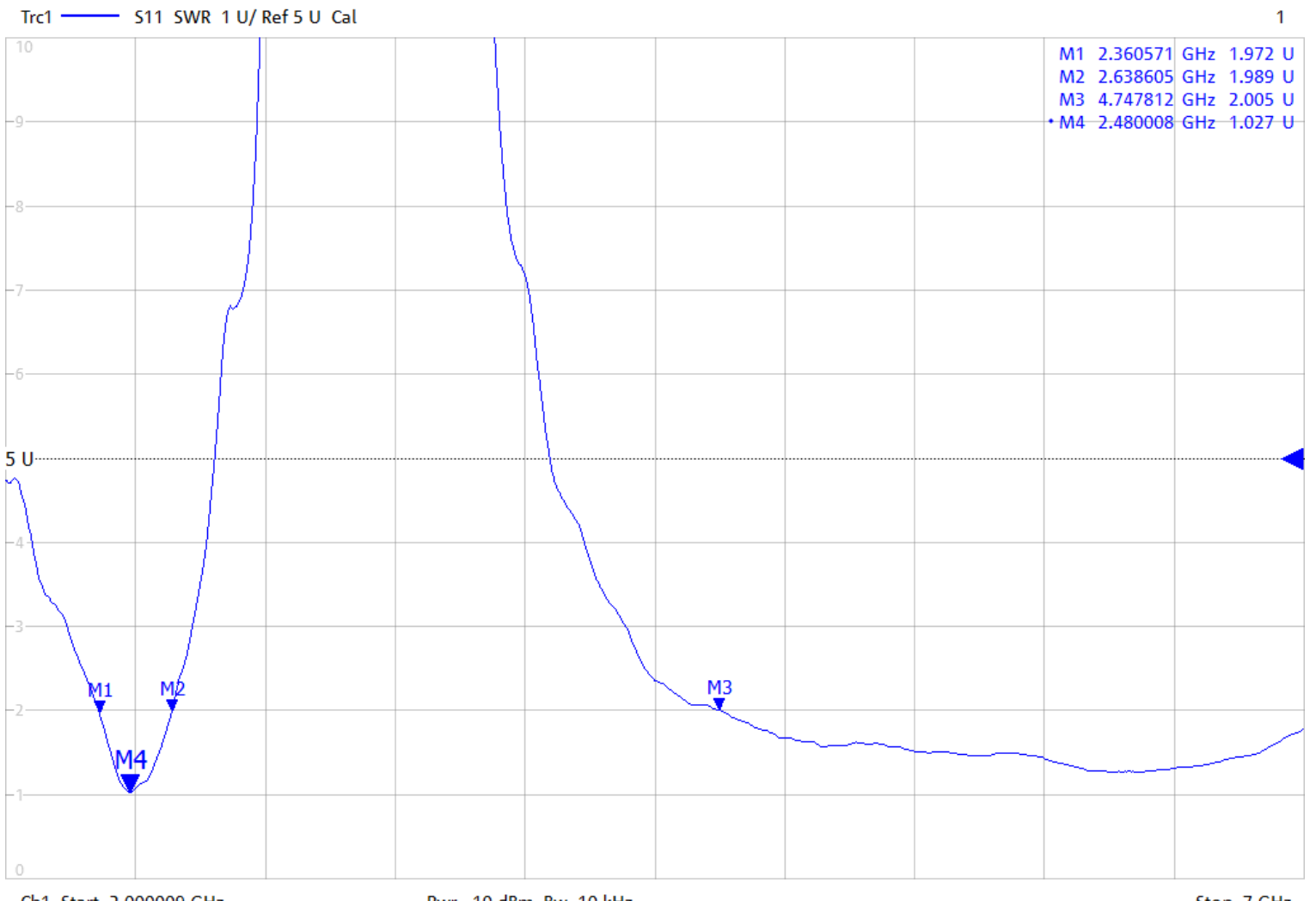

Ch1 Start $2.000009 \mathrm{GHz}$

Pwr $-10 \mathrm{dBm}$ Bw $10 \mathrm{kHz}$

Stop $7 \mathrm{GHz}$ 
Fig. 11. VSWR and S11 Value of Floating Single Band Wi-Fi Module Antenna \#1

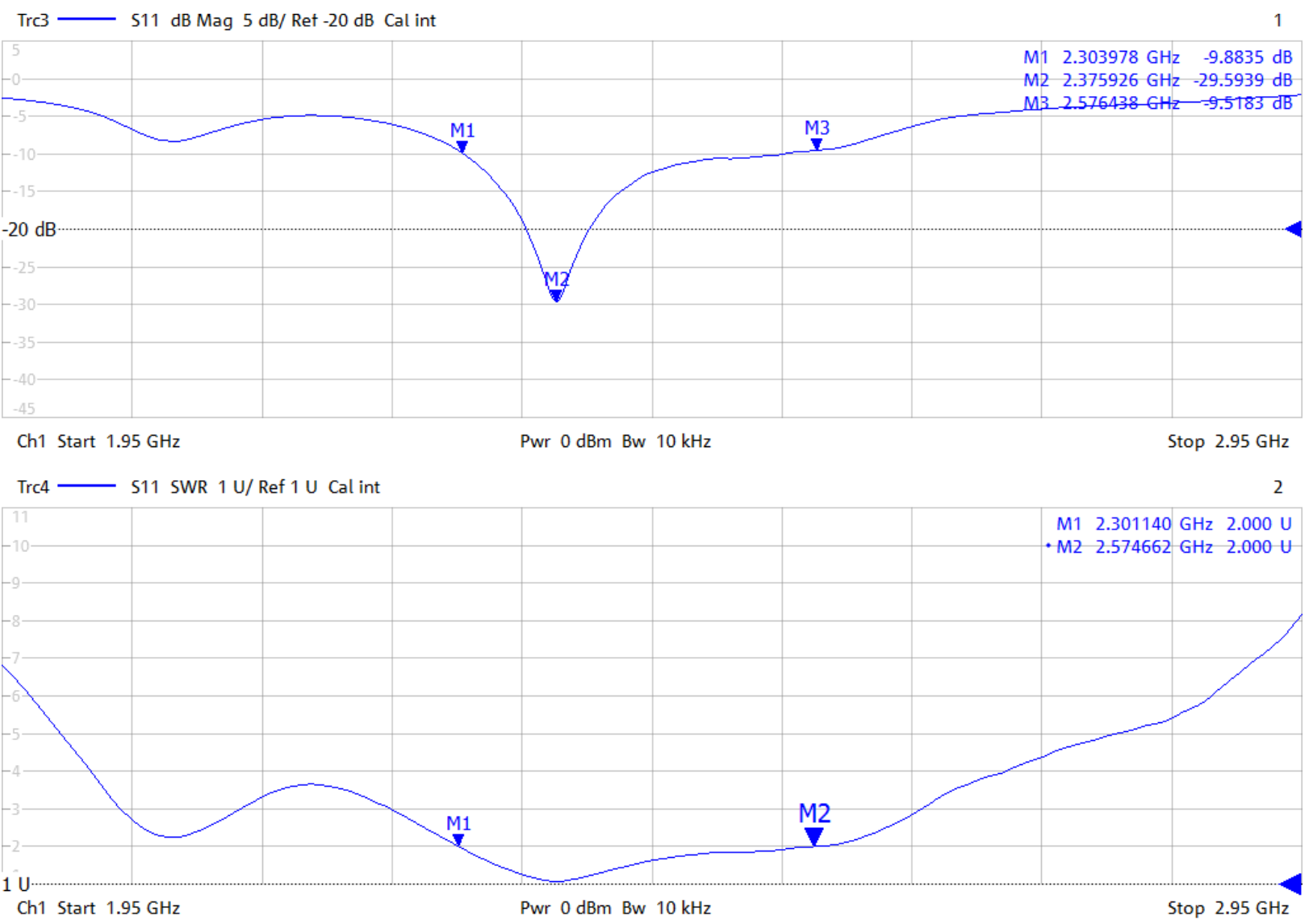

Fig. 12. VSWR and S11 Value of Floating Single Band Wi-Fi Module Antenna \#2

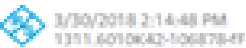

Tre3 — 511 ds Mag 5 dey Ref -20 dB Cal ins

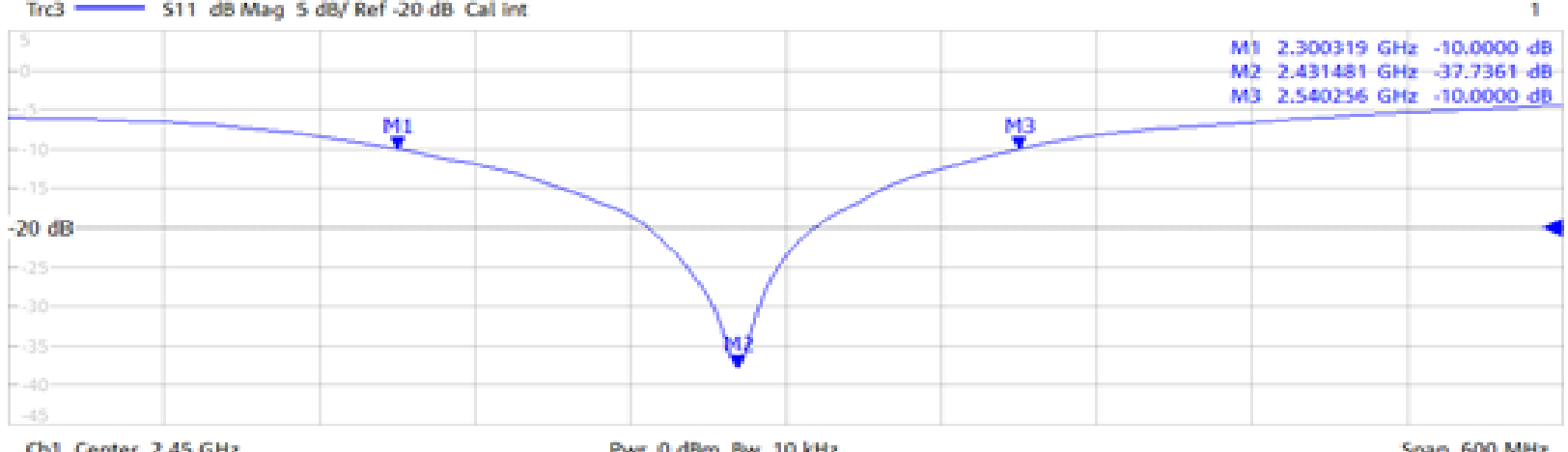

Ch1 Center $2.45 \mathrm{GHz}$

Tro4 - 511 SWR $500 \mathrm{~mW} /$ Ref $2.5 \mathrm{U}$ Call int

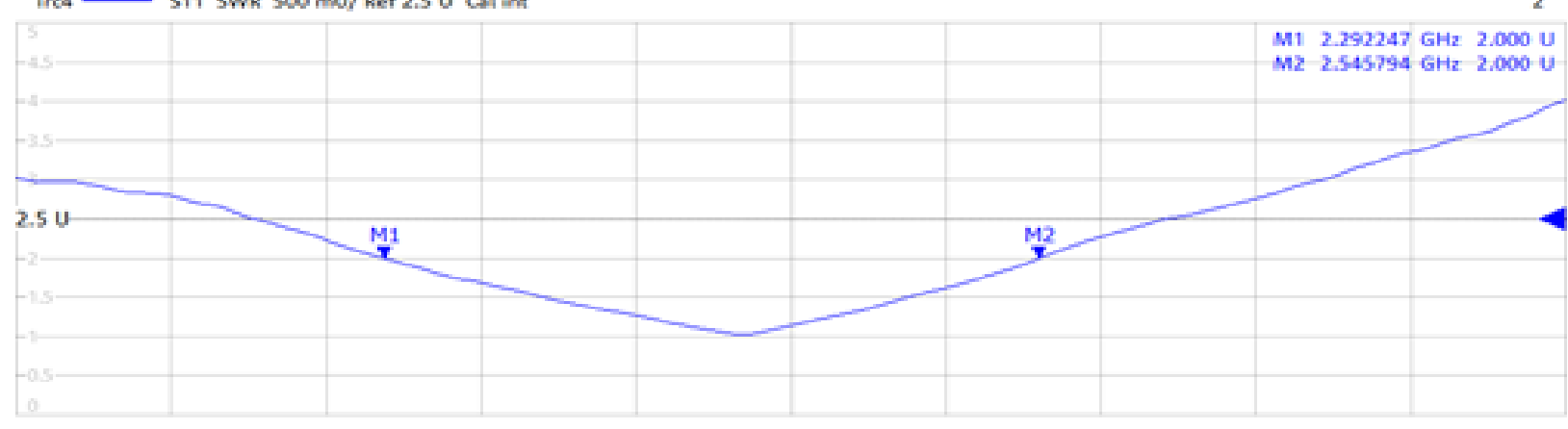




\subsection{Aim of the Study}

In the figures 2 and 4, actual Wi-Fi modules that are used in this study are shown. In figure 2, the inhouse design Wi-Fi module is shown where in 4 , the reference commercial WiFi module is shown. They are two different Wi-Fi modules with the same board sizes and they both will be used in two different products with the same television chassis. To mount the WiFi modules on the chassis, there must be a holder or a special slot structure on the chassis and it causes additional costs in manufacturing and allocates extra space on the chassis. Therefore, it is efficient to use both Wi-Fi modules on the same location on the chassis so there will be only one structure for $\mathrm{Wi}-\mathrm{Fi}$ modules to be mounted. It will simplify the product management and the manufacturing process. However, due to the different antenna characteristics of the modules, their antenna performances on the same location will be different.

Our goal was to determine a minimum distance to TV chassis materials such as plastic and metal for Wi-Fi module positioning in television chassis so that Wi-Fi signal receptions of both modules maintain a good quality over the Wi-Fi frequency spectrum.

Fabrication of household goods requires use of same materials in many configurations for many products. For instance, in fabrication of a television, same chassis may be used for two or more different models. Also, two or more different Wi-Fi modules can be used in the same chassis for many different models. This variety in product configurations forces designers to create practical rule of thumbs for design and integration of each critical component. In this study, the case is to create a rule of thumb for locating different Wi-Fi modules in same chassis. Two different Wi-Fi modules having different antenna characteristics naturally response to the environment differently. The goal of this study is to determine a safe distance from different materials of the chassis for both Wi-Fi modules so the mechanical design can have a common location for both modules in the product without sacrificing a great received signal quality. The received signal quality is directly related to the S11 parameters, hence the VSWR of the antennas (1). Therefore, the evaluation of the measurements will be based on S11 parameters.

\section{RESULTS AND DISCUSSION}

\subsection{Test Results and Comparison}

We obtained two tables, table 1-2, that show the frequency value when VSWR hits to 2 first (Band Low) and after (Band High) in $2.4 \mathrm{GHz}$ band regarding the type of obstacle and the distance from Wi-Fi module to the obstacle. Also, the frequency of lowest VSWR value is given as center frequency.

Measurements are made when the Wi-Fi modules were floating on air without surrounded by any material and when the modules were placed on a broad plastic or metal surface with different distances. 
Table 1. Measurement results of Antenna characteristics of Dual-Band Wi-Fi module.

\begin{tabular}{|c|c|c|c|c|c|}
\hline \multicolumn{2}{|c|}{ Wi-Fi Benchmark } & \multicolumn{2}{c|}{ 2,4 GHz Band } & 5 GHz Band \\
\hline $\begin{array}{c}\text { Distance d } \\
(\mathbf{m m})\end{array}$ & Obstacle & $\begin{array}{c}\text { Band Low } \\
(\mathbf{G H z})\end{array}$ & $\begin{array}{c}\text { Center Freq } \\
(\mathbf{G H z})\end{array}$ & $\begin{array}{c}\text { Band High } \\
(\mathbf{G H z})\end{array}$ & $\begin{array}{c}\text { Band Low } \\
(\mathbf{G H z})\end{array}$ \\
\hline \multicolumn{2}{|c|}{ Floating Antenna 1 } & 2,326 & 2,455 & 2,618 & 4,859 \\
\hline \multicolumn{2}{|c|}{ Floating Antenna 2 } & 2,361 & 2,480 & 2,639 & 4,748 \\
\hline 1 & Plastic & 2,242 & 2,410 & 2,572 & 4,774 \\
\hline 2 & Plastic & 2,301 & 2,420 & 2,597 & 4,774 \\
\hline 1 & Metal & 2,110 & 2,200 & 2,259 & 5,987 \\
\hline 2,5 & Metal & 2,090 & 2,185 & 2,449 & 5,817 \\
\hline 5 & Metal & 2,085 & 2,150 & 2,484 & 5,590 \\
\hline 7,5 & Metal & 2,085 & 2,135 & 2,560 & 5,376 \\
\hline 10 & Metal & 2,459 & 2,515 & 2,589 & 4,312 \\
\hline 12,5 & Metal & 2,444 & 2,520 & 2,629 & 5,266 \\
\hline 15 & Metal & 2,437 & 2,535 & 2,630 & 4,312 \\
\hline 17,5 & Metal & 2,422 & 2,515 & 2,627 & 4,430 \\
\hline 20 & Metal & 2,409 & 2,515 & 2,621 & 5,378 \\
\hline 22,5 & Metal & 2,38 & 2,510 & 2,621 & 5,164 \\
\hline
\end{tabular}

Table 2. Measurement results of Antenna characteristics of Single-Band Wi-Fi module

\begin{tabular}{|c|c|c|c|c|}
\hline \multicolumn{2}{|c|}{ Single Band Wi-Fi Module } & \multicolumn{3}{c|}{ 2,4 GHz Band } \\
\hline Distance d $(\mathbf{m m})$ & Obstacle & Band Low $(\mathbf{G H z})$ & Center Freq $(\mathbf{G H z})$ & Band High $(\mathbf{G H z})$ \\
\hline \multicolumn{2}{|c|}{ Floating Antenna 1} & 2,387 & 2,482 & 2,598 \\
\hline \multicolumn{2}{|c|}{ Floating Antenna 2} & 2,300 & 2,431 & 2,540 \\
\hline 1 & Plastic & 2,082 & 2,258 & 2,363 \\
\hline 2 & Plastic & 2,311 & 2,436 & 2,551 \\
\hline 1 & Metal & 2,579 & 2,590 & 2,606 \\
\hline 2,5 & Metal & 2,573 & 2,589 & 2,606 \\
\hline 5 & Metal & 2,405 & 2,505 & 2,561 \\
\hline 7,5 & Metal & 2,545 & 2,596 & 2,640 \\
\hline 10 & Metal & 2,239 & 2,429 & 2,525 \\
\hline 12,5 & Metal & 2,332 & 2,408 & 2,583 \\
\hline 15 & Metal & 2,282 & 2,372 & 2,512 \\
\hline 17,5 & Metal & 2,329 & 2,411 & 2,579 \\
\hline 20 & Metal & 2,388 & 2,481 & 2,596 \\
\hline 22,5 & Metal & 2,392 & 2,471 & 2,599 \\
\hline
\end{tabular}


Both tables show the shift in frequency response as expected. The antennas of both Wi-Fi modules are affected by the proximity to metal and plastic surfaces due to the changes in their impedances. Their operating frequency interval which is when the VSWR is below 2 shifted drastically regarding the distance between the module and the chassis surface.

Wi-Fi single band frequency spectrum covers from $2412 \mathrm{MHz}$ to $2472 \mathrm{MHz}$. The VSWR value below 2 within this frequency spectrum is an important criterion for the performance of the Wi-Fi modules. Therefore, the minimum distance to the chassis when both modules meet this criterion must be found to determine the location of the Wi-Fi module holder on the chassis.

\subsection{Conclusion}

The results clearly show that the two Wi-Fi modules, due to the structure of their different antenna structures, response differently to the change in distance to the plastic or metal chassis. However, the results also show that both Wi-Fi module have a good antenna performance when they have minimum $2 \mathrm{~mm}$ distance to plastic chassis and when they have 5 $\mathrm{mm}$ distance to metal chassis. In given circumstances when they have $2 \mathrm{~mm}$ distance to plastic chassis or when they have $5 \mathrm{~mm}$ distance to metal chassis, they both remains good antenna performance with VSWR below 2 within Wi-Fi spectrum.

Finding these minimum distances allows using only one place, therefore, one holder structure for both Wi-Fi modules and simplifies the manufacturing process and the design leading decrease in the manufacturing costs. 


\section{REFERENCES}

[1] H. T. Friis, "Noise figures of radio receivers", Proc. IRE, vol. 32, no. 7, pp.419-422, July, 1944

doi: 10.1109/JRPROC.1944.232049

[2] L. F. T. G. Amarai and M. S. Novo, "Effects of printed circuit board on the performance of tag antennas for passive RFID," 2017 Progress in Electromagnetics Research Symposium -

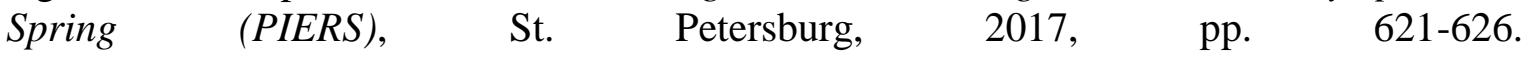
doi: 10.1109/PIERS.2017.8261815

[3] M. K. Mandal and M. Kahar, "A multiband robust planar antenna for wireless handheld devices," 2016 Asia-Pacific Microwave Conference (APMC), New Delhi, 2016, pp. 1-4. doi: 10.1109/APMC.2016.7931474

[4] Wang Shan, Guo Chenjiang, Zhou Yanqiu and Ding Jun, "A vector method for determining voltage standing wave ratio of radio communication," 2015 12th IEEE International Conference on Electronic Measurement \& Instruments (ICEMI), Qingdao, 2015, pp. 656660

[5] M. A. Al-Tarifi and D. S. Filipovic, "Multi-layer dielectric rod antenna with stable patterns over decade bandwidth," 2017 IEEE International Symposium on Antennas and Propagation \& USNC/URSI National Radio Science Meeting, San Diego, CA, 2017, pp. 505-506.

doi: 10.1109/APUSNCURSINRSM.2017.8072295 